\title{
Exploring changes in public transport use and walking following residential relocation: A British case study
}

\section{Paulus Teguh Aditjandra}

Newcastle University

paulus.aditjandra@newcastle.ac.uk

\author{
Xinyu (Jason) Cao \\ University of Minnesota \\ cao@umn.edu
}

\section{Corinne Mulley}

University of Sydney

corinne.mulley@sydney.edu.au

\begin{abstract}
The promotion of local sustainable travel is ever prominent within local transport plans, although it is still not well understood how the change to more sustainable and less carbon-based travel can be achieved. The objective of this study is to gain a better understanding of the travel choice mechanism following residential relocation. This paper uses a structural equations model and an ordered model to explore the drivers of public transport and walking use within an urban environment, using a quasi-longitudinal dataset from 10 communities in the metropolitan area of Tyne and Wear, in northeast England. The results show that changes in public transport use are determined by accessibility features of the built environment, alongside socio-demographic and travel attitude characteristics. Changes in walking, on the other hand, are determined mostly by built-environment characteristics. These findings suggest that a different approach is needed for the promotion of public transport use than for increasing walking trips (aside from walking to access public transport). The provision of public transport services needs to take into account the importance of the value of transport to users, to sufficiently attract and retain them. To promote walking, policy must focus on changes to the built environment (such as safety, travel accessibility, and the sociability of the environment), since it is changes in these characteristics that drive walking in the urban area.
\end{abstract}

\section{Article history:}

Received: November 29, 2013

Accepted: December 28, 2014

Available online: July 6, 2015

\section{Introduction}

This study examines the relationships between land-use and travel behavior, based on data from Tyne and Wear, in North East England. The objective is to gain a better understanding of the mechanism by which the variation in changes in travel behavior can be explained when households move between

neighborhoods. This is important because, while the evidence in the literature has been encouraging

Copyright 2015 Paulus Teguh Aditjandra, Xinyu (Jason) Cao \& Corinne Mulley

http://dx.doi.org/10.5198/jtlu.2015.588

ISSN: 1938-7849 | Licensed under the Creative Commons Attribution - Noncommercial License 3.0

The Journal of Transport and Land Use is the official journal of the World Society for Transport and Land Use (WSTLUR) and is published and sponsored by the University of Minnesota Center for Transportation Studies. This paper is also published with sponsorship from WSTLUR and the Institutes of Transportation Studies at the University of California, Davis, and the University of California, Berkeley. 
about the effect of the built environment on travel behavior (see, for example, Banister 2012; Ewing and Cervero 2010), there is still limited evidence of the mechanism or causality behind observed changes in travel behavior, especially in terms of public transport use, within a European context. Evidence from Northern California demonstrated that, after controlling for attitudes and changes in socio-demographic characteristics, changes in automobile use are affected by changes in spaciousness and accessibility of built-environment characteristics, while changes in walking trips are associated with changes in attractiveness, physical activity options, safety, and social aspects (Cao, Mokhtarian, and Handy 2007). The data from North East England showed that changes in driving behavior are affected by changes in safety factors, shopping accessibility, and social factors (Aditjandra, Cao, and Mulley 2012). This paper aims to report the analysis of changes in public transport use and walking, following residential relocation, using quasi-longitudinal household survey data from 10 selected neighborhoods in North East England collected in spring 2007. This study is one of the few applications of the structural equation model on quasi-longitudinal data that offers insights into the link between neighborhood design and travel choices.

\section{Recent research progress in Europe}

During the past three decades, land-use and travel-behavior research has enhanced our understanding of how transport engineers and planners use the tools of land-use and transportation planning to achieve sustainability that is economically efficient, environmentally sound, and socially acceptable. North American studies have demonstrated that density (including population, dwelling unit, and employment), diversity (land-use mix), design (street network characteristics), destination accessibility, distance to public transport, demand management (including parking) and demographics are the key drivers that influence travel behavior (Ewing and Cervero 2010). Attitudes in the context of residential self-selection were also found to influence travel behavior (Cao, Mokhtarian, and Handy 2009). Furthermore, the issue of quality of life through the impact of (physical) health and carbon emissions has also been identified as contributing to the way in which land-use policies shape travel behavior (Glaeser and Kah 2010; Heath et al. 2006). Recent developments in land-use and travel-behavior research, based on the extensive North American literature, have emphasized the process of plans and place-making and the evaluation of innovative local transport policies (Boarnet 2011).

Since many studies have summarized the research progress in North America, this review focuses on European studies. In Europe, a number of research clusters have addressed the relationships between land-use and travel behavior. In Athens, Greece, a study using the National Travel Survey demonstrated that residential density was the main determinant of mode choice- the denser an area, the less car use - and that socio-demographic characteristics (income, car ownership, household size, and public transport access) also played significant roles in affecting the use of the car (Milakis 2011). Another study, from the second largest Greek city, Thessaloniki, showed that the provision of effective public transport was not sufficient to promote sustainable mobility practice, as respondents generally preferred the car over public transport for commuting, where parking spaces are available. The presence of a child or children in the household was also identified as a determinant of car use over public transport (Tyrinopoulos and Antoniou 2012).

Scandinavian-based studies are characterized by the successful control of urban sprawl that has led, in turn, to reduced car dependence and increased population densities in cities (Næss et al. 2011; Næss 2012). Metropolitan-scale land-use variables were found to play a greater role than neighborhood-level variables in influencing car travel (Næss 2011). In terms of the mechanism of travel behavior change, a number of qualitative studies pointed to the way that the closest facilities were not always used, but that people wished to reduce travel distance/time for the best and most suitable facility (see, for example, Røe 
2001 and Tillberg 2001 as cited in Næss 2012). Moreover, a qualitative study in the Copenhagen metropolitan area demonstrated that people valued having the option to choose between facilities, beyond simply the shortest distance traveled (Næess 2005). These findings demonstrated the role of "preference" attitudes in a travel behavior change context.

Dutch-based studies, such as Maat and Timmermans (2009), van Wee (2011) and Maat and Arentze (2012), demonstrate a complex relationship between built environment and travel behavior. A trend of reductionist approach to car use has emerged, with the support of a shift from monocentric to polycentric urban forms and decentralization of local/regional responsibility for transport measures. The Dutch compact city policy has been shown to promote high levels of cycling and walking in mediumsized cities, although without significant changes in travel time and distance (Maat and Arentze 2012). A quantitative study on travel behavior change mechanisms following residential relocation demonstrated only marginal effects for new housing with compact city principles (Snellen and Hilbers 2007). The suggested reasons for this counter-intuitive outcome were that people who moved to the new building scheme were previously traveling above-average distances, with greater car use, due to personal circumstances such as education, employment, and life-cycle stage. A quantitative study on bicycle commuting demonstrated that attitudes toward cycling and colleagues' expectations helped explain being a commuter cyclist in the Netherlands (Heinen, Maat, and van Wee 2012).

German-based studies, such as Keller and Vance (2013) and Vance and Hedel (2008), showed that the government has adopted "decentralized concentration" to promote compact development and reduce increasing demand for car travel, even though greenhouse gas emissions from transport had reportedly decreased between 1990 and 2009. Additionally, heterogeneous landscape characteristics - such as the dense urban agglomeration in the former West Germany and the diffused urban sprawl in the former East Germany as a result of economic stagnation—were acknowledged in Schmidt (2011), as cited in Keller and Vance (2013). In terms of the causes of travel behavior change and attitudes, some German literature has engaged with the disciplines of lifestyle and mobility style grounds through the use of mobility biographies (Scheiner and Holz-Rau 2007, 2012). Residential relocation is one of the key events investigated, and these studies have demonstrated that changes in car use and public transport use were significantly determined by changes in car ownership, changes in household structure, and changes in public transport quality and satisfaction (Scheiner and Holz-Rau 2012). Weaker causal relationships were found for cycling and walking after residential relocation; changes in cycling were significantly affected by changes in shopping quality, while changes in walking were significantly influenced by changes in the number of children in the household, as well as by changes in shopping quality (Scheiner and Holz-Rau 2012). A parallel observation, with different data, revealed that key life events were relatively loosely associated with changes in mode use (Scheiner and Holz-Rau 2013).

The Belgian-based studies, such as van Acker, Derudder, and Witlox (2013), van Acker, Witlox, and Wee (2007), and van Acker and Witlox (2010), concluded that lower car ownership and reduced car use were associated with high density and mixed-use neighborhood settings, poor car access, and central locations (central business districts and/or railway station). Furthermore, the long tradition of suburbanization that exists in Belgium, dating back to the 19th century, appears to cause residents to perceive that they are living in more urbanized areas, since inexpensive public transport is complemented by a well-established network of railways and tramways and a housing policy that promotes inexpensive social housing within the suburbs (van Acker, Derudder, and Witlox 2013). Commuting travel behavior is determined by job densities, land-use mix, and access to public transport (van Acker and Witlox 2011). Additionally, a more pronounced effect of land-use was identified on simple work tours, as compared to more complex tours, suggesting the importance of trip-related characteristics (van Acker and Witlox 2011). Using different data, it was found that leisure trips were determined by 
subjective variables, i.e. lifestyles, residential and travel attitudes, in parallel with objective variables, such as the built environment, stage of life, car availability and mode choice (van Acker, Mokhtarian, and Witlox, 2011). This is especially true for car use and public transport use. For example, a traditional family lifestyle was strongly associated with car use, for active leisure activities. Further, it was concluded that ignoring subjective influences results in an underestimation of the effects of the built environment on modal choice for leisure trips (van Acker, Mokhtarian, and Witlox 2011).

Using different data sources and with different objectives, several recent British-based studies have addressed the relationship between travel behavior and urban form. An early but extensive UK study demonstrated that more than 50 percent of variation in travel patterns was explained by socioeconomic factors, while less than a third was explained by land-use (Stead 2001). A study using data from residents in England who had moved house within the previous two years to settlements designed to have some transport sustainability features (e.g., traffic calming measures, home zones) demonstrated mixed results (Susilo et al. 2012). For public transport use, the main determinants were car availability, distance to public transport stops and household size; for walking and cycling, surprisingly higher densities were associated with less walking within the neighborhood, while more cycling was determined by better connections between neighborhoods, secured bike storage, and low density housing (Susilo et al. 2012). A study using the Scottish Household Survey data showed that population density, land-use mix, and distance to city center were associated with the number of cars available to a household and thus with the number of car trips; increasing land-use mix and density reduced the frequency of car trips and single occupancy car trips (Ferguson and Woods 2010). Furthermore, a sample of residential relocation data demonstrated that a change in population density was negatively associated with a change in car use (Ferguson and Woods 2010). A different study, from four English cities, concluded that English suburbs were not very walkable at all, but when there are local facilities (such as local food shops, post offices, leisure centers, etc.), people use them (Barton, Horswell, and Millar 2012). Higher residential density is not recommended as the key spatial issue, whereas neighborhood location, form, integration (into the town/city), permeability, and service/facility catchment viability are recommended. This led to the recommendation of "localism" as the national agenda for planning (Barton, Horswell, and Millar 2012). Another observation, using suburbs in a typical medium-sized British city in North East England, demonstrated that the main determinants of vehicle miles driven (VMD) were car availability, driving licenses and employment, followed by travel preferences (i.e., car dependent attitude, pro-public transport, or pro-walking), and neighborhood characteristics at the margins (i.e., shopping/facilities accessibility, type of neighborhood: traditional vs suburban) (Aditjandra, Mulley, and Nelson 2009). Further, using the same data, with extended land-use variables to contrast between traditional and suburban neighborhoods, Aditjandra, Mulley, and Nelson (2013) demonstrated that attitudes toward residential spaciousness and safety factors are also associated with VMD.

\section{Active travel and the built environment}

While the understanding of the relationship between built environment and travel behavior has been improving, and more movements toward the adoption of "new urbanism" or "compact city" are evident as described above, one of the main gains from promoting access to destination (by the availability of active travel choices, i.e., walking and cycling) is the personal health benefit due to the physical activity involved. As a result, some researchers have defined built environments, which specifically suit active travel activity, to counter the traditional measure of travel behavior, i.e. car travel (Handy et al. 2002; Pikora et al. 2003). Early literature from the United States demonstrated that residents in traditional or neotraditional urban layouts undertook more active travel, compared to those in modern cul-de-sac layouts (Saelens, Sallis, and Frank 2003). In Britain, the negative health impacts derived from a car-oriented 
built environment have also gained attention; this has led to the promotion of walking and cycling and neighborhood revitalization as one of the main strategies to enhance public health (Rao et al. 2007). A French study found that more walking and cycling were evident in neighborhoods characterized by high accessibility to green spaces, proximity to facilities, and cycle path availability (Charreire et al. 2012).

In the United States, physical activity such as cycling has been discussed as a choice independent of environmental support, due to the lack of bicycle infrastructure (Moudon et al. 2005). However, a study specifically addressing neighborhood design and physical activity demonstrated that traffic volume and lighting were the main barriers to active travel, although the existence of neighborhood facilities (i.e., grocery stores, restaurants, convenient stores, etc.) were significantly associated with walking and moderate-intensity physical exercise (Lee and Moudon 2008). A more recent study, using data from residential relocation, demonstrated that moving to an activity-friendly neighborhood can positively affect physical activity levels and that this is especially true among residents who had previously been least active (Calise et al. 2013). Similar evidence was echoed in western Australia, with the use of a longitudinal study of residential relocation to demonstrate that the presence of recreational and active transport-related facilities in a neighborhood led to increases in recreational walking (Giles-Corti et al. 2013).

An early British study to promote walking and cycling for health purposes demonstrated that the most effective intervention was targeted behavior programs involving interested individuals or households (Ogilvie et al. 2004). A follow-up study showed generic interventions were not as successful, but that people can be encouraged to walk more by interventions that are tailored to their needs, targeted at the most sedentary or at those most motivated to change and delivered to individuals or households or groups (Ogilvie et al. 2007). The targeted approach was shown to increase walking in general — as well as walking as a mode of transport-by up to 30-60 minutes per week on average (Ogilvie et al. 2007). Cycling initiatives in England have also demonstrated positive effects, with significant increases in cycling to work reported (Goodman et al. 2013). Recent observations on the use of new walking and cycling infrastructure suggest these investments have catered more to the socioeconomically advantaged and less to the population who would benefit most from the health benefits, and thus they do not contribute as much to health and health equity goals (Goodman, Sahlqvist, and Ogilvie 2013).

\section{$4 \quad$ Public transport and the built environment}

The travel behavior literature has identified the significant effect of land-use characteristics on mode choice. Cervero and Kockelman (1997) was an early study that investigated the influences of land-use density, diversity, design — referred to as the 3D—on the probability of non-car travel.

Following Cervero and Kockelman (1997), there have been a variety of studies in different settings, although most relate to US experience. These studies show variations in the influence of land-use on mode choice, and some of the variations can be explained by different measurement of land-use variables and different methodologies. Kitamura, Mokhtarian, and Laidet (1997), in a study of San Francisco, did not use density or diversity but included a number of design variables and accessibility (extending 3D to 4D) to destinations such as rail stations and parks. Rajamani et al. (2003) included all four land-use measures in looking at the North American activity survey, whereas Zhang (2004) examined Boston and Hong Kong, using similar measurements for density and the quantitative results and found that elasticities of public transport trips to land-use factors were very similar between the two cities.

Ewing and Cervero (2010) undertook a meta-analysis of studies linking travel behavior and the built environment. This study noted the way in which the more recent studies have expanded the 4D to $5 \mathrm{D}$, adding the access to public transport, usually measured as a distance. Moreover, the increase in the number of studies relating travel to the built environment was motivated by public health concerns over the US obesity epidemic and was also echoed in some European studies, as discussed in the previous 
section. Ewing and Cervero (2010) noted the great variety in methodologies (16 different methods are noted) and different levels of aggregation. The meta-analysis does, however, provide information, on a more consistent basis, for the impact of the built environment on walking and public transport use. The weighted average elasticities of walking and public transport use, with respect to density and diversity, are similar, although walking is more sensitive to job density than the demand for public transport. However, walking is much more influenced by the built environment design (intersection or street density and the proportion of four-way intersections), whereas public transport use is more influenced by the distance to the public transport stop. This evidence suggests that a walkable neighborhood is also an environment that is more favorable to public transport use, whereas a design incorporating high intersection density and good street connectivity incentivizes more walking and more public transport use. Importantly, of the land-use variables, density is less important than design and diversity in terms of weighted elasticities.

\section{$5 \quad$ Research design and hypothesis}

As the above literature review identifies, there is significant strength in the research into how the built environment is linked to the issue of mode choice. In the United States, research has been undertaken in the transport domain, the health domain, and the planning communities, often with collaboration between the disciplines. This literature has shown how neighborhood design can contribute to making travel by private car a less attractive option, thus contributing to the sustainability agenda. However, land-use agendas in the United States are very different from those of mainland Europe and Britain.

The literature review also identifies the growing interest in this subject, as indicated by the number of studies. However, the research community appears to be different. The sustainability agenda, achieved or encouraged by the built environment, is echoed in both mainland Europe and Britain, although in practical terms, mainland Europe appears to have been more successful in implementation-for example, the Dutch compact city movements. The research community is the town planning community, which has been looking at the opportunities where the issue has been debated in the town planning and medical communities, but rarely in the transport arena. This makes the evidence from this study particularly important.

Methodologically, many early studies, in particular, have found strong associations between the built environment and travel behavior. However, it was not until Handy, Cao, and Mokhtarian (2005) that serious consideration was given to how the causation between these elements could be demonstrated. A very big problem surrounded the issue of self-selection: Is what we are observing in a particular neighborhood the result of people choosing to live there or, put another way, is the observed association the result of unmeasured attitudes affecting both? In our study, we therefore introduce the attitudinal variables in the relationship between travel behavior and land-use, taking into account residential preferences and travel attitudes in the methodological design and thereby explicitly addressing the issue of residential self-selection, as discussed extensively in Bohte, Maat, and van Wee (2009) and Cao, Mokhtarian, and Handy (2009).

Structural equation model (SEM) was chosen as the analytical approach because of its capability to address the causal relationship of the multi-dimensional factors associated with land-use and travel behavior, as discussed earlier. A review of methodologies to address residential self-selection in travelbehavior studies pointed to the benefits gain of using a longitudinal structural equations modeling design approach (Mokhtarian and Cao 2008). Moreover, a number of recent studies using SEM to address the link between transportation and land-use studies (see, for example, Cao, Mokhtarian, and Handy 2007; de Abreu e Silva, Morency, and Goulias 2012; Galdames, Tudela, and Carrasco 2011; Scheiner and Holz-Rau 2007, 2012; van Acker et al. 2011) have successfully given new insights toward 
better understanding of transport policy making. Further review of SEM appropriateness for this study is reported in Aditjandra et al. (2012).

This paper uses a (quasi-) longitudinal approach to examine changes in public transport use and changes in walking, recorded by survey participants who had moved residence within a certain timeframe. This is in contrast to cross-sectional analysis pertaining to travel behavior change or quasi-longitudinal data to examine changes in the amount of car driving (Aditjandra, Mulley, and Nelson 2013, and Aditjandra, Cao, and Mulley 2012, respectively). In addressing the hypotheses of how the causal relationships developed and whether neighborhood characteristics contribute to the changes in travel behavior, we assume that socioeconomic variables and attitudes are exogenous within the relationships between the four dimensions, as demonstrated in Figure 1. Although previous studies have made significant progress, as noted above, there is still limited quantification of causation, or evidence on the mechanism, of changes in travel behavior using longitudinal data and, specifically, on public transport use within the European context-more especially in the United Kingdom. This paper contributes specifically to this research gap.

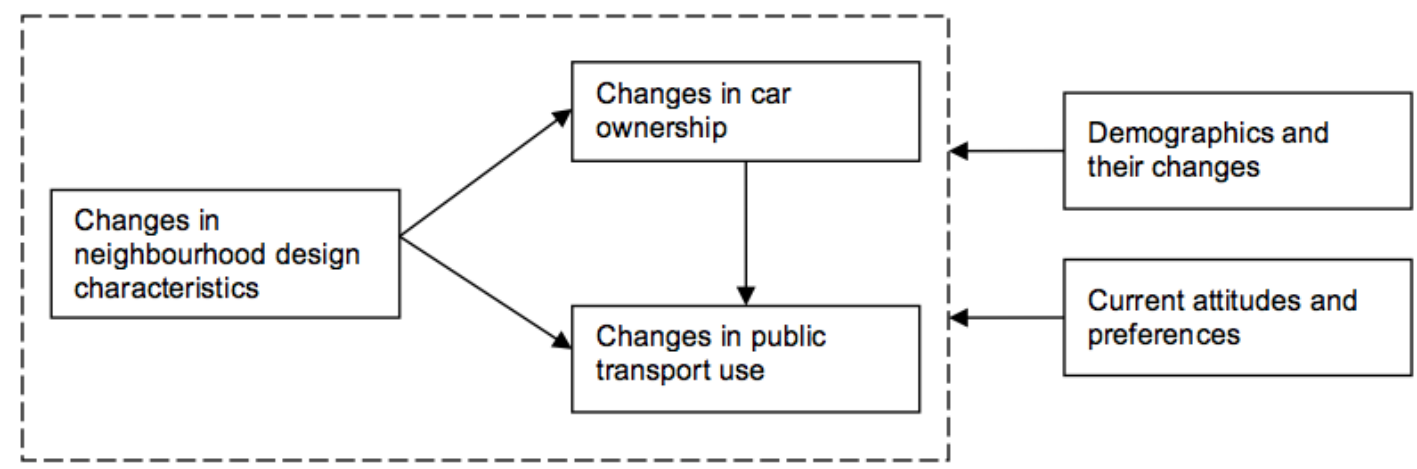

Figure 1: Structural equation model (SEM) design for public transport use (adapted from Aditjandra, Cao, and Mulley 2012)

\section{Data and analysis}

This section describes the collection and manipulation of the data to construct relevant variables for the model. Since the objective of the study is to examine a British case, the selection of neighborhoods to represent the typical British residential neighborhoods is important. Differences in urban form are created through the choice of 10 areas to represent five districts of the Tyne and Wear metropolitan area, in North East England. The neighborhoods were selected to vary systematically by neighborhood type (traditional street layout or suburban street layout), neighborhood size, and the five districts of the metropolitan conurbation.

The neighborhood unit was captured by reference to the lowest administration area used in the 2001 British Census data — the Lower Layer Super Output Area (LSOA). The Tyne and Wear metropolitan area contains 719 different LSOAs in total and, on average, a LSOA consists of 1500 households, with 7500 individual persons. The potential neighborhoods were screened, district by district, to ensure that income and other characteristics were above the average for the area. To control for these characteristics, the Index of Multiple Deprivation (IMD) 2004 was used, weighted by seven aspects: income, employment, health, education, barriers to housing and services, crime and living environment, and a UK measure of the deprivation of an area. The purpose of this screening was to find neighborhoods where people would choose to live, rather than areas where housing might be allocated on the basis of need or affordability, as preferences in the choice of the built environment are being considered. 
To combine the census screening and neighborhood design screening, Google Earth was used to capture the aerial view of a short list of potential neighborhoods, as well as to identify the homogeneity of street layout within the LSOA. A total of 190 LSOAs from the 38 highest IMD of each district were image-captured and analyzed in this way. After filtering the potential neighborhoods, through controlling for income (higher IMD relative to the average of the district) and sustainable mobility (the percentage of walking, cycling, and public transport use), the most representative residential neighborhoods were accordingly selected as the areas for the case study. A detailed description of the neighborhood "hotspot" methodology can be seen in Aditjandra, Mulley, and Nelson (2013).

This paper studied 219 respondents who reported they had moved to their current residence within the last eight years. In the pilot, prior to the main survey, five years was used as the threshold, but it was observed that a significant number of people reported their relocation within six, seven, and eight years and above-up to 20-plus years (Aditjandra 2007). Following an internal research group meeting that considered the ability to recall travel behavior and perceived built environment characteristics prior to relocation up to eight years previously, it was agreed to both increase the number of respondents for the (quasi) longitudinal analysis and to increase the time threshold in the main survey to eight years. Furthermore, the role of mobility biography studies (as conducted in Germany) that have pointed out the importance of life events such as residential relocation in changing travel behavior was acknowledged (see, for example, Scheiner and Holz-Rau 2007, 2012, 2013). The survey captured respondents' sociodemographic variables, including gender, age, economic status, educational background, household income, household size, and number of children, as well as changes in household income, household size, and number of children, before and after household relocation. Detailed sample characteristics of these movers can be seen in Aditjandra, Cao, and Mulley (2012). When working with samples, in order to understand whether results might be generalized to that population, it is desirable to identify whether the sample represents the population. Population data for residents who moved within the last eight years are not available. However, since the focus of our study is on explaining the relationships of other variables to travel behavior, rather than on describing travel behavior per se, these differences are not expected to materially affect the results (Babbie 1998; Groves 1989).

The questionnaire was designed to capture changes in travel behavior that result from different neighborhood characteristics. This was planned by asking respondents, who had moved to their current address within the target timescale, to indicate how they travel now, as compared to before they moved. This was done on a five-point scale from "a lot less" to "a lot more." This variable indicates respondents' changes in public transport use and walking behavior in the models.

Neighborhood characteristics and neighborhood preferences were measured, using 27 statements divided into six aspects of neighborhood design. The questionnaire design was loosely based on Handy, Cao, and Mokhtarian (2005), but there were a number of differences. In this study, the preference statements were grouped under different subheadings of neighborhood design aspects; the motivation for this was to make it easier for the respondents to provide a context to the questions asked.

These statements were measured using a four-point scale from "not at all true" to "entirely true" to obtain respondents' opinions on the perceived neighborhood characteristics. Respondents were asked to rate the characteristics of their current neighborhood, as well as the neighborhood in which they were previously a resident. In identifying the residents' preference for the same neighborhood characteristics in selecting their residence, a four-point scale from "not at all important" to "extremely important" was used. Travel attitudes/preferences were also measured, using a series of 28 statements on a five-point Likert scale from "strongly disagree" to "strongly agree."

For the changes in public transport use, this paper uses a structural equation model methodology to investigate links between neighborhood design and travel behavior and follows the two-step 
estimation approach, recommended by Anderson and Gerbing (1988). The first step is to perform a factor analysis to provide latent constructs, which are subsequently used as continuous variables in the structural model. The advantage of using factor analysis in this way is that it has been shown to reduce complexity in the development of the model in the second step. Thus, common Factor Analysis (CFA, called principle axis factoring in SPSS) with oblique rotation was used as a first step, to identify the latent constructs underlying the 27 statements on neighborhood characteristics and the 28 statements on travel attitudes/preferences. The CFA is more appropriate than principal component analysis when the purpose of the procedure is to identify latent constructs (Widaman 1993), and oblique (Oblimin) rather than orthogonal rotation was used because, in theory, the latent factors of neighborhood design perceptions and preferences and travel attitudes might correlate with each other and would not be statistically independent (Field 2005). The criterion "Eigenvalue $>1$ " was used to determine the number of factors. Through this analysis, perceived and preferred neighborhood characteristics were extracted into seven factors: safety, travel accessibility, residential spaciousness, social factors, shopping/facilities accessibility, outdoor space accessibility, and neighborhood unattractiveness. The travel attitudes were reduced to eight factors, including pro-public transport use, travel minimizing awareness, dislike of cycling, positive utility of travel, safety of car, pro-walking, dislike of travel, and car dependence. Factor loadings are shown in Table 1. Accordingly, these factors (latent constructs) are treated as observed continuous variables in developing the structural equation model. 
Table 1: Factors of neighborhood characteristics and travel attitude

\begin{tabular}{|c|c|c|}
\hline Neighborhood Characteristics Factors & Statements & Loadings \\
\hline \multirow[t]{6}{*}{ Safety } & Safe neighborhood for walking & .829 \\
\hline & Low crime rate within neighborhood & .777 \\
\hline & $\begin{array}{l}\text { Safe neighborhood for children to play } \\
\text { outdoors }\end{array}$ & .686 \\
\hline & $\begin{array}{l}\text { Low level of car traffic on neighborhood } \\
\text { streets }\end{array}$ & .673 \\
\hline & Quiet Neighborhood & .603 \\
\hline & Good street lighting & .364 \\
\hline \multirow[t]{5}{*}{ Travel accessibility } & $\begin{array}{l}\text { Easy access to a good public transport } \\
\text { service (bus/metro/rail) }\end{array}$ & .877 \\
\hline & $\begin{array}{l}\text { Good public transport service (bus/ } \\
\text { metro/rail) }\end{array}$ & .804 \\
\hline & $\begin{array}{l}\text { Easy access to highway network (main } \\
\text { road) }\end{array}$ & .417 \\
\hline & $\begin{array}{l}\text { Pavements_-easy walking routes } \\
\text { throughout the neighborhood }\end{array}$ & .394 \\
\hline & Local shops within walking distance & .353 \\
\hline \multirow[t]{3}{*}{ Residential spaciousness } & Adequate space of garden at the front & .919 \\
\hline & Adequate space of garden at the rear & .857 \\
\hline & $\begin{array}{l}\text { Adequate off-street parking (garages or } \\
\text { driveways) }\end{array}$ & .560 \\
\hline \multirow[t]{4}{*}{ Social factors } & $\begin{array}{l}\text { Lots of people out and about within the } \\
\text { neighborhood }\end{array}$ & .787 \\
\hline & Lots of interaction among neighbors & .665 \\
\hline & $\begin{array}{l}\text { Diverse neighbors in terms of ethnicity, } \\
\text { race and age }\end{array}$ & .465 \\
\hline & $\begin{array}{l}\text { Economic situation of neighbors similar } \\
\text { to my level }\end{array}$ & .386 \\
\hline \multirow[t]{4}{*}{ Shopping/facilities accessibility } & $\begin{array}{l}\text { Easy access to a district shopping center } \\
\text { (Tesco, ASDA, etc.) }\end{array}$ & .913 \\
\hline & Easy access to town center & .713 \\
\hline & $\begin{array}{l}\text { Other amenities/facilities such as a } \\
\text { community/leisure center or facilities for } \\
\text { children available nearby }\end{array}$ & .468 \\
\hline & \begin{tabular}{|l|} 
Local shops within walking distance \\
\end{tabular} & .316 \\
\hline \multirow[t]{3}{*}{ Outdoor space* accessibility } & Parks and open spaces nearby & .586 \\
\hline & $\begin{array}{l}\text { Extension of cycle routes beyond the } \\
\text { neighborhood }\end{array}$ & .576 \\
\hline & $\begin{array}{l}\text { Other amenities/facilities such as a } \\
\text { community/leisure center or facilities for } \\
\text { children available nearby }\end{array}$ & .309 \\
\hline \multirow[t]{3}{*}{ Neighborhood* unattractiveness } & Attractive appearance of neighborhood & -.771 \\
\hline & $\begin{array}{l}\text { High level of neighborhood's upkeep } \\
\text { (well maintained) within the neighbor- } \\
\text { hood }\end{array}$ & -.723 \\
\hline & Variety in housing style & -.440 \\
\hline
\end{tabular}

* Factors with eigenvalue $<1$ by parallel analysis but eigenvalue $>$ than 95 percentile of random data 


\begin{tabular}{|c|c|c|}
\hline Travel Attitude Factors & Statements & Loadings \\
\hline \multirow[t]{3}{*}{ Pro-public transport use } & I like traveling by public transport & .876 \\
\hline & $\begin{array}{l}\text { I prefer to take public transport than drive whenever } \\
\text { possible }\end{array}$ & .870 \\
\hline & $\begin{array}{l}\text { Public transport can sometime be easier for me than } \\
\text { driving }\end{array}$ & .743 \\
\hline \multirow[t]{7}{*}{ Travel minimizing awareness } & $\begin{array}{l}\text { I prefer to organize errands so that I make as few } \\
\text { trips as possible }\end{array}$ & .634 \\
\hline & $\begin{array}{l}\text { Fuel efficiency is an important factor for me in } \\
\text { choosing a vehicle }\end{array}$ & .617 \\
\hline & I try to limit my driving to help improve air quality & .598 \\
\hline & $\begin{array}{l}\text { The price of fuel affects the choices I make about my } \\
\text { daily travel }\end{array}$ & .570 \\
\hline & $\begin{array}{l}\text { I often use the telephone/Internet to avoid having to } \\
\text { travel somewhere }\end{array}$ & .399 \\
\hline & $\begin{array}{l}\text { When I need to buy something, I usually prefer to } \\
\text { get it at the closest store possible }\end{array}$ & .393 \\
\hline & $\begin{array}{l}\text { Vehicles should be taxed on the basis of the amount } \\
\text { of pollution they produce }\end{array}$ & .368 \\
\hline \multirow[t]{3}{*}{ Dislike-cycling } & I prefer to cycle rather than drive whenever possible & -.930 \\
\hline & I like riding a bicycle & -.782 \\
\hline & Cycling can sometimes be easier for me than driving & -.751 \\
\hline \multirow[t]{2}{*}{ Positive utility of travel } & Travel time is generally wasted time & -.643 \\
\hline & $\begin{array}{l}\text { The only good thing about traveling is arriving at } \\
\text { your destination }\end{array}$ & -.618 \\
\hline \multirow[t]{3}{*}{ Safety of car } & $\begin{array}{l}\text { Traveling by car is safer overall than taking public } \\
\text { transport }\end{array}$ & .801 \\
\hline & Traveling by car is safer overall than walking & .775 \\
\hline & Traveling by car is safer overall than riding a bicycle & .488 \\
\hline \multirow[t]{3}{*}{ Pro-walking* } & I like walking & .730 \\
\hline & I prefer to walk rather than drive whenever possible & .728 \\
\hline & Walking can sometimes be easier than driving & .582 \\
\hline \multirow[t]{2}{*}{ Dislike-travel* $^{*}$} & $\begin{array}{l}\text { The trip to/from work is a useful break between } \\
\text { home and work (the importance of your journey to } \\
\text { work) }\end{array}$ & -.720 \\
\hline & I use my time to/from work productively & -.618 \\
\hline \multirow[t]{2}{*}{ Car dependent* } & I need a car to do many things I like to do & .632 \\
\hline & Getting to work without a car is a hassle & .551 \\
\hline
\end{tabular}

Extraction method: Principal axis factoring. Rotation method: Oblimin with Kaiser normalization

\section{$7 \quad$ Model construction and results}

In this study, changes in travel behavior (public transport use and walking), changes in built environment, and changes in car ownership were initially selected as endogenous variables. Changes in travel behavior were captured from the quasi-longitudinal survey that asked respondents to recall their changes in travel to various activities (mainly to work), before and after residential relocation. Changes in built environment factors were computed by taking the difference between factor scores for current neighborhoods and the corresponding scores for previous neighborhoods. In a longitudinal analysis, the direc- 
tions of the hypothesized effects are particularly important, due to the temporal sequences of events. Previous research has well documented that residential choice is a long-term choice, car ownership is a medium-term decision, and travel behavior is conditional on both residential choice and car ownership choice (Ben-Akiva and Atherton 1977); and recently revisited by Van Acker, Van Wee, and Witlox (2010). Therefore, we assumed that changes in the built environment create changes in car ownership and travel behavior, with changes in car ownership, in turn, impacting on changes in travel behavior. It was hypothesized that endogenous variables are also affected by a number of exogenous variables: demographic characteristics and their changes, and current travel attitudinal factors. We tested the impacts of all changes in the built environment variables on changes in car ownership and changes in travel behavior; we also tested the impacts of demographics and their changes and current attitudes on the three variables above. We kept only significant variables.

With the qualifying sample $(\mathrm{N}=170)$, the model for public transport use has an acceptable fit with RMSEA of 0.000; CFI of 1.000; and SRMR of 0.025. Although Hoelter (1983) recommended a critical sample size of 200 to achieve sufficient statistical power, Schreiber et al. (2006) stated that 10 observations per free parameter are also acceptable. Our final model contains 11 free parameters; our sample size therefore meets the threshold.

Figure 2 presents the relationships between built environment (BE), socio-demographic characteristics (SD), attitudes (A), and travel behavior (TB) using the conceptual model presented earlier. The preference for "shopping/facilities accessibility" BE features is related to changes in "public transport use" in two ways. First, an individual with a preference for "shopping/facilities accessibility" was directly and positively associated with changes in "public transport use." Second, an individual who prefers "shopping/facilities accessibility" was more likely to find a neighborhood whose "shopping/facilities accessibility" BE features were higher than those of their previous neighborhood. Changes in "shopping/ facilities accessibility" BE features are negatively associated with changes in car ownership, which in turn has a negative association with changes in "public transport use." Changes in "travel accessibility" BE features are positively associated with changes in "public transport use." Individuals with preferences for "travel accessibility" and also "pro-public transport" were positively associated with changes in "public transport use." 


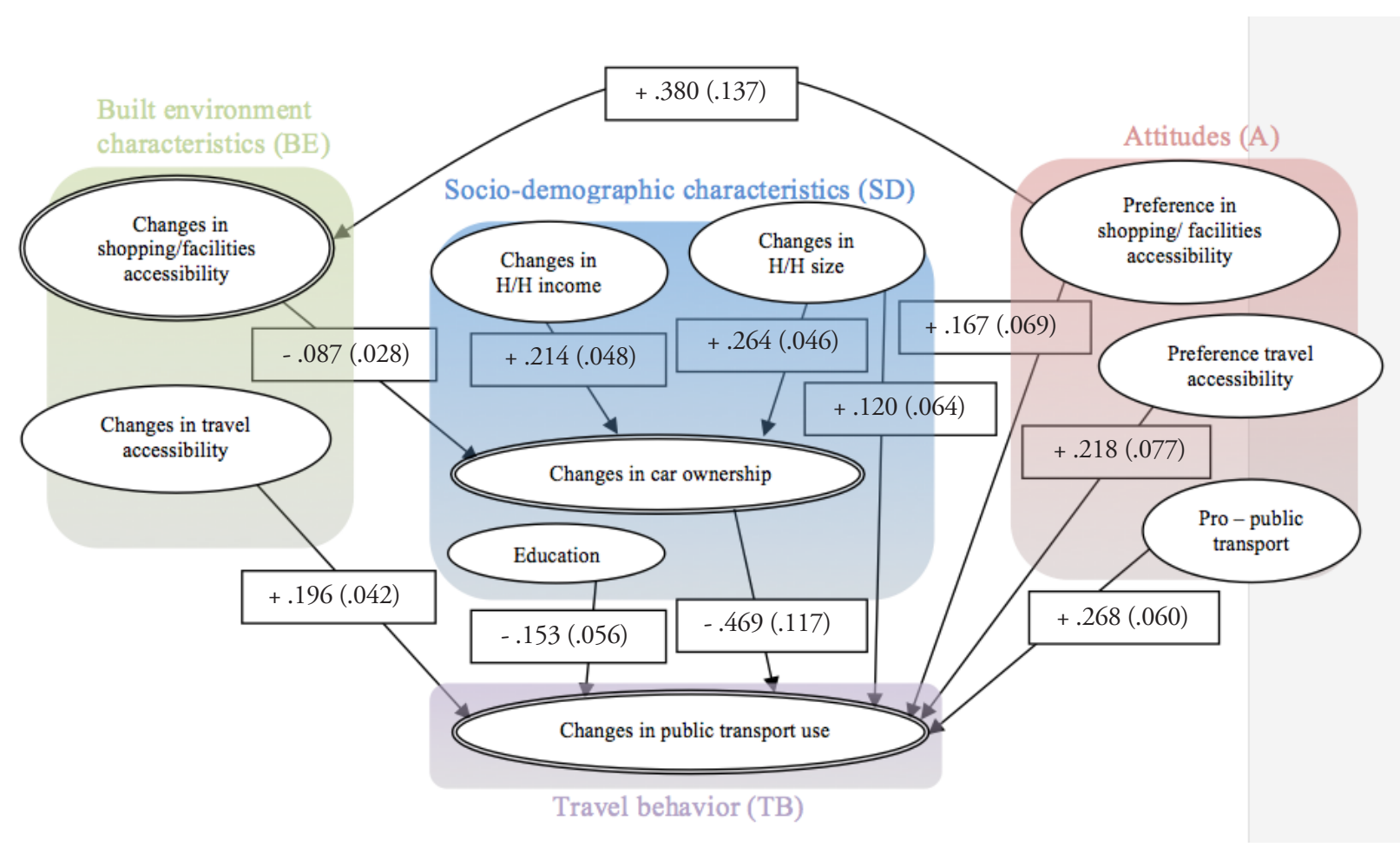

Figure 2: Public transport path analysis model

Note: The SEM was estimated using the maximum likelihood method with bootstrap to overcome potential deviation from normal assumption. The numbers in parentheses next to the coefficients are standard errors.

\section{$8 \quad$ Discussion and conclusion}

This paper applies a structural equations model and ordered logit model to a British quasi-longitudinal dataset to understand the relationship between neighborhood design and travel behavior, in the form of changes in public transport use and walking. It complements previous analysis on changes in car use (Aditjandra et al. 2012).

Recent literature in the relationship between travel behavior and land-use demonstrates that physical activities, derived from public transport use and from walking, are some of the key elements of a healthier lifestyle. In the meantime, the reshaping of the city, toward development of the compact city type, depends on improving understanding of how the residents will adapt to a new and more sustainable built environment. European-based transportation land-use research has generally demonstrated that a number of land-use characteristics, at different spatial scale, can influence travel behavior change, but the key determinants remain socio-demographic characteristics, through mainly car ownership and household size (among other characteristics). Other aspects, such as the role of historical development and of life events, have been the highlights of some of these European studies. In terms of travel behavior change mechanism, following residential relocation, the quality of public transport systems and shopping facilities accessibility were the key drivers in Germany (Scheiner and Holz-Rau 2012). Our study, using British data, is in support of this conclusion, but extends insight further by demonstrating the role of travel attitudes in influencing changes in public transport use and walking, and thus avoids the 
underestimation of the effects of the built environment role on travel behavior (Næss 2005; van Acker et al. 2011).

Table 2: Ordered logit model for changes in walking

\begin{tabular}{|c|c|c|}
\hline \multirow[b]{2}{*}{ Changes in built environment characteristics } & Coefficient (standard error) & p-value \\
\hline & & \\
\hline Changes in safety & $.314(.126)$ & .013 \\
\hline Changes in travel accessibility & $.283(.111)$ & .011 \\
\hline Changes in social factors environment & $.221(.120)$ & .066 \\
\hline Changes in outdoor space accessibility & $.307(.119)$ & .010 \\
\hline Changes in neighborhood unattractiveness & $-.317(.096)$ & .001 \\
\hline \multicolumn{3}{|l|}{ Changes in socio-demographic characteristics } \\
\hline Changes in the number of children in the household & $.526(.192)$ & .006 \\
\hline \multicolumn{3}{|l|}{ Travel attitude characteristics } \\
\hline Safety of car attitude & $-.357(.153)$ & .020 \\
\hline Pro-walking attitude & $.537(.154)$ & .000 \\
\hline
\end{tabular}

$\mathrm{N}=192$; Pseudo $\mathrm{R}^{2}=0.1075$

This paper demonstrates that changes in public transport use and walking are determined by the four dimensions of the conceptual framework, in particular the linkages between neighborhood characteristics and travel behavior, as described in this study. The accessibility features of the built environment, such as the provision of public transport services, significantly change the level of public transport use-and thus walking — within a neighborhood. Additionally, changes in the accessibility features of the built environment — such as changes to shopping facilities — can also indirectly increase the level of public transport use, through a reduction in car ownership. These findings suggest that the creation of transit-oriented development, supported by shopping/facilities built environment features, would attract both the use of public transport and walking, as shopping and associated activities are linked closely to the use of public transport. In contrast, other built environment features, such as safety, social factors, outdoor spaces, and neighborhood attractiveness, are much more associated with changes in walking behavior, which may signal this mode's use in leisure and more local travel. Additionally, since most areas within our sample (eight out of the 10 selected neighborhoods) are not within easy walking distance of employment centers, such as city center/business districts, car driving or public transport modes are the only feasible options for travel to work.

In conclusion, there must be different approaches to the promotion of public transport use and the increasing of walking trips (aside from walking to access public transport). The provision of public transport services needs to take into account the importance of the value of the transport to the user, to sufficiently attract and retain users. From a policy point of view, this suggests better public transport services will lead to more public transport use, although this must be sensitive to different neighborhoods, with changes in the ease of access to public transport and accessibility of shopping and other facilities being the main determinants. In contrast, to promote more walking behavior, policy must focus on the changes to the built environment (such as safety, travel accessibility, and the sociability of the environment), since it is changes in these characteristics that drive walking in the urban area, with more trips being likely in an environment that is "walking friendly."

It is worth noting that the built environment variables measured in this study are respondents' perceptions of their residential environment. Although it is these perceptions that drive their behavior, planners need to understand the relationships between the perceptions and objective built environment measures, so that they can plan for change. However, the connections have not been well studied and 
hence merit further investigation. Moreover, perceived neighborhood characteristics may be vulnerable to reporting bias; for example, individuals who participate in walking may be more aware of the existence of amenities and non-motorized transportation infrastructure nearby. This bias may inflate the impact of neighborhood characteristics on walking. Thus, a true longitudinal study is required to obtain precise estimates of built environment influence on walking, as shown in Giles-Corti et al. (2013). In the future, a parallel study, in which a true longitudinal design is compared to a quasi-longitudinal design, when the true longitudinal project is to be implemented, would help to quantify the impact of reporting and recall biases.

\section{$9 \quad$ Acknowledgments}

The generosity of Thomas H. Zunder, freight and logistics expert at Newcastle University, to keep let time for the reporting of this Ph.D data analysis is gratefully appreciated. Thanks also to Ann Zunder for the proof reading. 


\section{References}

Aditjandra, P. T. 2007. Relationships between urban form and travel behavior: A case study of suburban vs traditional neighborhoods in North Tyneside, North East England, with specific reference to the accessibility attribute. Universities Transport Studies Group (UTSG) 39th Annual Conference, Harrogate, January 3-5, 2007. 2.1D: Land Use and Location. http://www.utsg.net/web/index. php?page $=2007---$ leeds.

Aditjandra, P. T., X. Cao, and C. Mulley. 2012. Understanding neighborhood design impact on travel behavior: An application of structural equations model to a British metropolitan data. Transportation Research Part A: Policy and Practice 46(1): 22-32. doi:10.1016/j.tra.2011.09.001.

Aditjandra, P. T., C. Mulley, and J. D. Nelson. 2009. Neighborhood design impact on travel behavior: A comparison of UK and US experience. Projections 9: 29-56.

Aditjandra, P. T., C. Mulley, and J. D. Nelson. 2013. The influence of neighborhood design on travel behavior: Empirical evidence from North East England. Transport Policy 26: 54-65. doi:10.1016/j. tranpol.2012.05.011.

Anderson, J. C., and D. W. Gerbing. 1988. Structural equation modeling in practice: A review and recommended two-step approach. Psychological Bulletin 103: 411-423.

Babbie, E. R. 1998. The Practice of Social Research (8th ed.). Belmont, CA: Wadsworth.

Banister, D. 2012. Viewpoint: Assessing the reality-Transport and land use planning to achieve sustainability. Journal of Transport and Land Use 5(3): 1-14. doi:10.5198/jtlu.v5i3.388

Barton, H., M. Horswell, and P. Millar, P. 2012. Travel neighborhood accessibility and active travel. Planning Practice and Research 27(2): 177-201.

Ben-Akiva, M., and T. J. Atherton. 1977. Methodology for short-range travel demand predictions: Analysis of carpooling alternatives. Journal of Transport Economics and Policy 11: 224-261.

Boarnet, M. G. 2011. A broader context for land use and travel behavior, and a research agenda. Journal of the American Planning Association 77(3): 197-213. doi:10.1080/01944363.2011.593483.

Bohte, W., K. Maat, and B. van Wee. 2009. Measuring attitudes in research on residential self-selection and travel behavior: A review of theories and empirical research. Transport Reviews 29(3): 325-357.

Calise, T. V., T. Heeren, W. DeJong, S. C. Dumith, and H. W. Kohl. 2013. Do neighborhoods make people active, or do people make active neighborhoods? Evidence from a planned community in Austin, Texas. Preventing Chronic Disease 10(2): E102. doi:10.5888/pcd10.120119.

Cao, X., P. L. Mokhtarian, and S. L. Handy. 2007. Do changes in neighborhood characteristics lead to changes in travel behavior? A structural equations modeling approach. Transportation 34(5): 535556. doi:10.1007/s11116-007-9132-x.

Cao, X., P. L. Mokhtarian, and S. L. Handy. 2009. Examining the impacts of residential self-selection on travel behavior: A focus on empirical findings. Transport Reviews 29(3): 359-395.

Cervero, R., and K. Kockelman. 1997. Travel demand and the 3Ds: Density, diversity, and design. Transportation Research Part D: Transport and Environment 2(3): 199-219. doi:10.1016/S13619209(97)00009-6

Charreire, H., C. Weber, B. Chaix, P. Salze, R. Casey, A. Banos, A., D. Badariotti, E. Kesse-Guyot, S. Hercberg, C. Simon, and J. Oppert. 2012. Identifying built environmental patterns using cluster analysis and GIS: Relationships with walking, cycling and body mass index in French adults. International Journal of Behavioral Nutrition and Physical Activity 9(59): 1-11. doi:10.1186/1479-58689-59.

De Abreu e Silva, J., C. Morency, and K. G. Goulias. 2012. Using structural equations modeling to unravel the influence of land use patterns on travel behavior of workers in Montreal. Transportation Research Part A: Policy and Practice 46(8): 1252-1264. doi:10.1016/j.tra.2012.05.003. 
Ewing, R., and R. Cervero. 2010. Travel and the built environment. Journal of the American Planning Association 76(3): 265-294. doi:10.1080/01944361003766766.

Ferguson, N., and L. Woods. 2010. Travel and mobility. In Dimensions of the Sustainable City, Vol. 2: 53-74, edited by M. Jenks and C. Jones. Dordrecht, Netherlands: Springer Netherlands. doi:10.1007/978-1-4020-8647-2.

Field, A. 2005. Discovering Statistics Using SPSS (2nd ed.). London: SAGE Publication Ltd.

Galdames, C., A. Tudela, and J. A. Carrasco. 2011. Exploring the role of psychological factors in mode choice by a latent variables approach. Transportation Research Record 2230(1): 68-74. doi:10.3141/2230-08.

Giles-Corti, B., F. Bull, M. Knuiman, G. McCormack, K. Van Niel, A. Timperio, H. Christian, S. Foster, M. Divitini, N. Middleton, and B. Boruff. 2013. The influence of urban design on neighborhood walking following residential relocation: Longitudinal results from the RESIDE study. Social Science and Medicine 77: 20-30. doi:10.1016/j.socscimed.2012.10.016.

Glaeser, E. L., and M. E. Kahn. 2010. The greenness of cities: Carbon dioxide emissions and urban development. Journal of Urban Economics 67(3): 404-418. doi:10.1016/j.jue.2009.11.006.

Goodman, A., J. Panter, S. J. Sharp, and D. Ogilvie. 2013. Effectiveness and equity impacts of townwide cycling initiatives in England: A longitudinal, controlled natural experimental study. Social Science and Medicine 97: 228-237. doi:10.1016/j.socscimed.2013.08.030.

Goodman, A., S. Sahlqvist, and D. Ogilvie. 2013. Who uses new walking and cycling infrastructure and how? Longitudinal results from the UK iConnect study. Preventive Medicine 57(5): 518-524. doi:10.1016/j.ypmed.2013.07.007.

Groves, R. M. 1989. Survey Errors and Survey Costs. New York: John Wiley and Sons.

Handy, S. L., M. G. Boarnet, R. Ewing, and R. E. Killingsworth. 2002. How the built environment affects physical activity: Views from urban planning. American Journal of Preventive Medicine 23(2 Suppl): 64-73. URL: http://www.ncbi.nlm.nih.gov/pubmed/12133739.

Handy, S. L., X. Cao, and P. L. Mokhtarian. 2005. Correlation or causality between the built environment and travel behavior? Evidence from Northern California. Transportation Research Part D: Transport and Environment 10(6): 427-444. doi:10.1016/j.trd.2005.05.002.

Heath, G. W., R. C. Brownson, J. Kruger, R. Miles, K. E. Powell, and L. T. Ramsey. 2006. The effectiveness of urban design and land use and transport policies and practices to increase physical activity: A systematic review. Journal of Physical Activity and Health 3(Suppl 1): S55-S76.

Heinen, E., K. Maat, and B. van Wee. 2012. The effect of work-related factors on the bicycle commute mode choice in the Netherlands. Transportation 40(1): 23-43. doi:10.1007/s11116-012-9399-4.

Hoelter, D. R. 1983. The analysis of covariance structures: Goodness-of-fit indices. Sociological Methods and Research 11:325-344.

Keller, R., and C. Vance. 2013. Landscape pattern and car use: Linking household data with satellite imagery. Journal of Transport Geography 33: 250-257. doi:10.1016/j.jtrangeo.2013.07.006.

Kitamura, R., P. L. Mokhtarian, and L. Laidet. 1997. A micro-analysis of land use and travel in five neighborhoods in the San Francisco Bay Area. Transportation 24: 125-158.

Lee, C., and A. V. Moudon. 2008. Neighborhood design and physical activity. Building Research and Information 36(5): 395-411. doi:10.1080/09613210802045547.

Maat, K., and T. Arentze. 2012. Feedback effects in the relationship between the built environment and travel. The Planning Review 48(3): 6-15. doi:10.1080/02513625.2012.759341.

Maat, K., and H. J. P. Timmermans. 2009. Influence of the residential and work environment on car use in dual-earner households. Transportation Research Part A: Policy and Practice 43(7): 654-664. doi:10.1016/j.tra.2009.06.003. 
Milakis, D. 2011. Exploring the direct and indirect effects of urban form on travel choices. The case of Athens, Greece. International Journal of Sustainable Development 14(1/2): 16-29.

Mokhtarian, P. L., and X. Cao. 2008. Examining the impacts of residential self-selection on travel behavior: A focus on methodologies. Transportation Research Part B: Methodological 42(3): 204-228. doi:10.1016/j.trb.2007.07.006.

Moudon, A. V., C. Lee, A. D. Cheadle, C. W. Collier, D. Johnson, T. L. Schmid, and R. D. Weather. 2005. Cycling and the built environment, a US perspective. Transportation Research Part D: Transport and Environment 10(3): 245-261. doi:10.1016/j.trd.2005.04.001.

Næss, P. 2005. Residential location affects travel behavior - but how and why? The case of Copenhagen metropolitan area. Progress in Planning 63(2): 167-257. doi:10.1016/j.progress.2004.07.004

Næss, P. 2011. "New urbanism" or metropolitan-level centralization? Journal of Transport and Land Use 4(1): 25-44. doi:10.5198/jtlu.v4i1.170.

Næss, P. 2012. Urban form and travel behavior: Experience from a Nordic context. Journal of Transport and Land Use 5(2): 21-45. doi:10.5198/jtlu.v5i2.314.

Næss, P., A. Strand, T. Næss, and M. Nicolaisen. 2011. On their road to sustainability?: The challenge of sustainable mobility in urban planning and development in two Scandinavian capital regions. Town Planning Review 82(3): 285-316. doi:10.3828/tpr.2011.18.

Ogilvie, D., M. Egan, V. Hamilton, and M. Petticrew. 2004. Promoting walking and cycling as an alternative to using cars: Systematic review. BMJ (Clinical Research Ed.) 329(7469): 763. doi:10.1136/ bmj.38216.714560.55.

Ogilvie, D., C. E. Foster, H. Rothnie, N. Cavill, V. Hamilton, C. F. Fitzsimons, and N. Mutrie. 2007. Interventions to promote walking: Systematic review. BMJ (Clinical Research Ed.) 334(7605): 1204. doi:10.1136/bmj.39198.722720.BE.

Pikora, T., B. Giles-Corti, F. Bull, K. Jamrozik, and R. Donovan. 2003. Developing a framework for assessment of the environmental determinants of walking and cycling. Social Science and Medicine, 56(8): 1693-703. http://www.ncbi.nlm.nih.gov/pubmed/12639586.

Rajamani, J., C. Bhat, S. Handy, G. Knaap, and Y. Song. 2003. Assessing impact of urban form measures on nonwork trip mode choice after controlling for demographic and level-of-service effects. Transportation Research Record 1831(1): 158-165. doi:10.3141/1831-18.

Rao, M., S. Prasad, F. Adshead, and H. Tissera. 2007. The built environment and health. The Lancet 370(9593): 1111-1113. doi:10.1016/S0140-6736(07)61260-4.

Saelens, B. E., J. F. Sallis, and L. D. Frank. 2003. Environmental correlates of walking and cycling: Findings from the transportation, urban design, and planning literatures. Annals of Behavioral Medicine 25(2): 80-91.

Scheiner, J., and C. Holz-Rau. 2007. Travel mode choice: Affected by objective or subjective determinants? Transportation 34(4): 487-511. doi:10.1007/s11116-007-9112-1.

Scheiner, J., and C. Holz-Rau. 2012. Changes in travel mode use after residential relocation: A contribution to mobility biographies. Transportation 40(2): 431-458. doi:10.1007/s11116-012-9417-6.

Scheiner, J., and C. Holz-Rau. 2013. A comprehensive study of life course, cohort, and period effects on changes in travel mode use. Transportation Research Part A: Policy and Practice 47: 167-181. doi:10.1016/j.tra.2012.10.019.

Schreiber, J. B., A. Nora, F. K. Stage, E. A. Barlow, and J. King. 2006. Reporting structural equation modeling and confirmatory factor analysis results: A Review. Journal of Educational Research 99(6): 323-337.

Snellen, D. M. E. G. W., and H. D. Hilbers. 2007. Mobility and congestion impacts of Dutch Vinex Policy. Tijdschrift Voor Economische En Sociale Geografie 98(3): 398-406. 
Stead, D. 2001. Relationships between land use, socioeconomic factors, and travel patterns in Britain. Environment and Planning B: Planning and Design 28(4): 499-528. doi:10.1068/b2677.

Susilo, Y. O., K. Williams, M. Lindsay, and C. Dair. 2012. The influence of individuals' environmental attitudes and urban design features on their travel patterns in sustainable neighborhoods in the UK. Transportation Research Part D: Transport and Environment 17(3): 190-200. doi:10.1016/j. $\operatorname{trd} .2011 .11 .007$.

Tyrinopoulos, Y., and C. Antoniou. 2012. Factors affecting modal choice in urban mobility. European Transport Research Review 5(1): 27-39. doi:10.1007/s12544-012-0088-3.

Van Acker, V., B. Derudder, and F. Witlox. 2013. Why people use their cars while the built environment imposes cycling. The Journal of Transport and Land Use 6(1): 53-62. doi:10.5198/jtlu.v6i1.288

Van Acker, V., P. L. Mokhtarian, and F. Witlox. 2011. Going soft: On how subjective variables explain modal choices for leisure travel. European Journal of Transport and Infrastructure Research 11(2): $115-146$.

Van Acker, V., B. Van Wee, and F. Witlox. 2010. When transport geography meets social psychology: Toward a conceptual model of travel behavior. Transport Reviews 30(2): 219-240. doi:10.1080/01441640902943453.

Van Acker, V., and F. Witlox. 2010. Car ownership as a mediating variable in car travel behavior research using a structural equation modeling approach to identify its dual relationship. Journal of Transport Geography 18(1): 65-74. doi:10.1016/j.jtrangeo.2009.05.006.

Van Acker, V., and F. Witlox. 2011. Commuting trips within tours: How is commuting related to land use? Transportation 38(3): 465-486. doi:10.1007/s11116-010-9309-6.

Van Acker, V., F. Witlox, and B. Van Wee. 2007. The effects of the land use system on travel behavior: A structural equation modeling approach. Transportation Planning and Technology 30(4): 331-353.

Van Wee, B. 2011. Evaluating the impact of land use on travel behavior: The environment versus accessibility. Journal of Transport Geography 19(6): 1530-1533. doi:10.1016/j.jtrangeo.2011.05.011.

Vance, C., and R. Hedel. 2008. On the link between urban form and automobile use: Evidence from German survey data. Land Economics 84(1): 51-65. doi:10.1353/lde.2008.0044.

Widaman, K. F. 1993. Common factor analysis versus principal component analysis: Differential bias in representing model parameters? Multivariate Behavioral Research 28(3): 263-311.

Zhang, M. 2004. The role of land use in travel mode choice: Evidence from Boston and Hong Kong. Journal of the American Planning Association 70(3): 344-360. doi:10.1080/01944360408976383. 